\title{
The relationship of job stress with self-efficacy among nurses working in hospitals of Semnan University of Medical Sciences, Iran
}

\author{
Jamileh Mahdizadeh', Faezeh Daihimfar ${ }^{2}$ and Mehdi Kahouei*3 \\ ${ }^{1}$ Medical Faculty, Semnan University of Medical Sciences, Semnan, Iran. \\ ${ }^{2}$ Student Research Committee, Nursing and Allied Health Faculty, Semnan University of Medical Sciences, \\ Semnan, Iran \\ ${ }^{3}$ Social Determinant of Health Research Center, Nursing and Allied Health Faculty, Semnan University of \\ Medical Sciences, Semnan, Iran ${ }^{3}$ Department of Entomology and Agril. Zoology,Institute of Agricultural \\ Sciences, Banaras Hindu University, Varanasi-221005, India
}

\begin{abstract}
The individual's perception of stress is essential in its experience and on the other hand, the same stressful events create different effects in people, so the question is whether capable nurses have more or less stress? This study was conducted to determine the relationship between self-efficacy and job stress among nurses. Participants in this study were nursing staffs of affiliated hospitals of Semnan University of Medical Sciences in Iran in 2015-2016. The results showed that $62.7 \%$ of the nursing staffs who had not self-efficacy, had mild job stress and between the levels of job stress and self-efficacy of the participants was significant $(\mathrm{P}<0.001)$. There were significant negative relationships among role overload $(B=-0.26, P=0.003)$, role insufficiency $(B=-0.58, P<0.001)$, role ambiguity $(B=-0.455, P<0.001)$, role boundary $(\mathrm{B}=-0.706, \mathrm{P}<0.001)$ and responsibility $(\mathrm{B}=-0.207, \mathrm{P}=0.022)$ with the participants' self-efficacy. The results of this study showed that job stress among nurses influences on the personal, emotional and cognitive effectiveness in nurses and can bring some organizational outcomes such as reduced properly function in the workplace.
\end{abstract}

KEY WORDS: JOB STRESS, SELF-EFFICACY, NURSES, IRAN

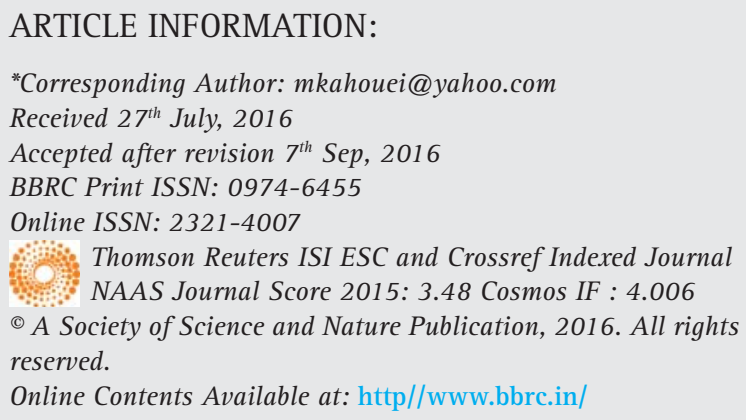




\section{INTRODUCTION}

Health care workers experience stress in proportion to their job involvement, which among them the nurses are the largest service providers in the health system (Yazdi Moghaddam, 2009) and in Iran, nurses account about 80 per cent of employment in the health care system and nursing tasks (Farsi and et al., 2010). Nurses are at the forefront of health care providers (Toloei and et al., 2006), and in jobs where human contact is normally more important, there are more stressful situations due to unpredictable circumstances (Gholam Nezhad and Nikpeyma, 2009).

On the other hand, apart from stress, self-efficacy is also of great importance in the nursing profession. Selfefficacy is a kind of personality factor having an impact on dealing with environmental pressures. It is also an important and effective concept in Bandura's social cognitive theory (2000). In this theory, cognitive processes in human behavior play a decisive role. People with high self-efficacy choose more challenging to moderately difficult goals, feel more relaxed, believe in themselves more, and show more insistent efforts (Pajares, 2002). Since long-term job stresses lead to burnout, emotional conflict, personality disorder, loss of sense of individual acceptance of the work of other individuals in the work environment (Motie and et al., 2010).

Thus, several studies have been conducted on occupational stress among nurses. For example, Hayes et al. (2015) in a study of over 194 public hospital nurses in Thailand concluded that $26 / 2 \%$ of the studied subjects suffered from severe job stress. In the study carried out by Motie et al. (2010), it was shown that 51/7 of studied nurses had moderate stress and $\% 11$ had severe stress. Research shows that occupational self-efficacy is considered an important predictor of job performance (Judge and Bono, 2001).

In this regard, some earlier studies have been conducted on the efficacy of nurses, Olson et al. (2012), where it has been shown that the individual's self-efficacy beliefs has influence on the behavior, effort and the time spent for dealing with resistance against stress. Some studies have also shown the association between increased efficacy and improved performance of nurses. For instance, studies by Lim and et al. (2004), indicate that understanding the synergies in the self-efficacy of nurses can improve nursing and professional measures and ultimately leads to improved clinical practices to patient care in the nursing profession. The above studies show that stress status and self-efficacy among nurses are frequently studied, yet the relationship between these two categories among nurses has not been analyzed. On the one hand, because stress is not always caused by stressful sources, but the individual's perception of stress is essential in its experience and on the other hand, the same stressful events create different effects in people, so the question is whether capable nurses have more or less stress? This study was conducted to determine the relationship between self-efficacy and job stress among nurses.

\section{MATERIAL AND METHODS}

Participants in the present study were nursing staffs of affiliated hospitals of Semnan University of Medical Sciences in Iran in 2015-2016. Census sampling was used in this study. A total of 532 questionnaires were distributed; 424 were returned, which represented a response rate of 79.6\%. Ethics approval was obtained from the Semnan University of Medical Ethics Committee (IR.SEMUMS. REC.1394.196). A covering letter was prepared for distribution with the survey document, which described the purposes of the study and explained that a response to the survey would indicate the consent of the participant to take part in the research. It also assured participants of the confidentiality of their responses.

Two questionnaires were used in this study. It was divided into five sections. The first questionnaire was Osipow's job stress questionnaire. It has been included 60 questions and six sections such as role overload, role insufficiency, role ambiguity, role boundary, responsibility and physical environmental. The second questionnaire was Scherer's self-efficacy questionnaire. It has been included 17 questions. The participants' attitudes on each item were measured on a 5-point Likert type scale, where very low $=1$, low $=2$, somewhat $=3$, high $=4$ and very high $=5$. The questionnaires have been distributed and returned to the researcher within 72 hours.

Means and standard deviations, in dependent- samples $\mathrm{T}$ and liner regression were used to analyze the data.

\section{RESULTS AND DISCUSSION}

$78.1 \%$ was female, $94.6 \%$ had bachelor degree and age average was 32.6. (Table1) 62.7\% of the nursing staffs who had not self-efficacy, had mild job stress and between the levels of job stress and self-efficacy of the participants was significant $(\mathrm{P}<0.001)$. (Table2) There were significant negative relationships among role overload $(B=-0.26, P=0.003)$, role insufficiency $(\mathrm{B}=-0.58, \mathrm{P}<0.001)$, role ambiguity $(\mathrm{B}=-0.455, \mathrm{P}<0.001)$, role boundary $(\mathrm{B}=-0.706, \mathrm{P}<0.001)$ and responsibility $(\mathrm{B}=-0.207, \mathrm{P}=0.022)$ with the participants' self-efficacy. (Table3)

Results of the present study showed that there was a significant relationship between the level of job stress and self-efficacy in the nurses. The findings suggest that 


\begin{tabular}{|c|c|c|c|}
\hline \multicolumn{4}{|c|}{ Table1: Nursing staffs' characteristics } \\
\hline Characteristics & Groups & $\mathrm{N}$ & $\%$ \\
\hline \multirow[t]{2}{*}{ sex } & Male & 93 & 21.9 \\
\hline & Female & 330 & 78.1 \\
\hline \multirow[t]{2}{*}{ Education } & Bachelor degree & 401 & 94.6 \\
\hline & Master degree & 22 & 5.4 \\
\hline Age (Year) & \multicolumn{3}{|l|}{${ }^{*} 32.6 \pm 9.9$} \\
\hline $\begin{array}{l}\text { Work experiences } \\
\text { (Year) }\end{array}$ & \multicolumn{3}{|l|}{ * $8.82 \pm 7.54$} \\
\hline
\end{tabular}

Table2: The relationship between self-efficacy and job stress level of the participants

\begin{tabular}{|l|l|l|l|}
\hline \multirow{2}{*}{ Self-efficiency } & \multicolumn{2}{|l|}{ Is there self-efficacy? } & P-value \\
\cline { 2 - 3 } & $\begin{array}{l}\text { No } \\
\mathrm{N}(\%)\end{array}$ & $\begin{array}{l}\text { Yes } \\
\mathrm{N}(\%)\end{array}$ & \\
\hline Normal & $10(16.9)$ & $26(7.1)$ & \multirow{3}{*}{$<0.001$} \\
\hline Mild & $37(62.7)$ & $295(80.8)$ & \\
\cline { 1 - 3 } Moderate & $10(16.9)$ & $44(12.1)$ & \\
\hline
\end{tabular}

the level of job stress influences on nurses' ability to control and deal with problems. In addition, the results showed that the increase in the role overload of nurses contributes to their $0.26 \%$ reduced efficacy. Nurses experience stress if they do not have enough time to do their psychological support for patients or the number of employees is not sufficient to cover the work (Dickinson and Wright, 2008).

In a study by Lee and Wrong (2002), the main stressful factors were workload and responsibilities of the role. The results indicated that as the amount of work by nurses at the same time increases, their beliefs about their ability to cope in certain situations and deal with problems are reduced (Burgess and et al., 2010; Brackett and et al., 2010). The results showed that the nurses' feelings of their role insufficiency contribute to \%58 in their reduced self-efficacy impact.

The data of an investigation, by Youssefian et al. (2015), showed that the mean score of role insufficiency among operating room staff was 33.6. Also the study carried out by Bahrami et al. (2012), showed that 64.9\% of self-insufficient nurses had stress. In another study by Abdi and Shahbazi (2002) 54.1\% of nurses were found to be suffering from stress in this area. The results showed that when nurses feel that their work environment needs are inconsistent with their skills and education, they are less able to control stressful events in their life and cannot influence or manage the stressful situations in order to realize their desirable future and prevent adverse outcomes. This situation rears worries, disappointments and discouragement among nurses (Bandura, 2000). Results showed that increasing role ambiguity in nurses to 0.455 contributes in reducing self-efficacy. Youssefian et al's study (2015) also showed that the average stress among nurses in the operating room was 36.59 .

Recently, Raj (2016) also found that $40.5 \%$ of ICU nurses in hospitals suffer from role ambiguity. The results suggest that if nurses are ambiguous in their nursing tasks, and are not able to properly assess them, or in other words they are unaware of the priorities and expectations of the workplace and benchmark value, it can lead to nurses to choose simple purposes instead of challenging or fairly difficult ones. It means that they are not able to visualize assignments as challenges that must dominate over them, hence they will not feel calm; they cannot believe themselves more and show less effort in their profession. As a result, they cannot take advantage of more useful learning strategies, their powerful abilities for remembering and reminding to function better in their assignments (Pajares, 2002).

The results of this study showed that the role boundary contributes 0.706 to reduced self-efficacy among nurses. Bahrami et al.(2012), found that male nurses were more stressful than female nurses in terms of role boundary. Abdi and Shahbazi (2002) found that 62.5\% of ICU nurses were within the range of stressful occupational role boundary. The results suggest that if nurses feel that there is a conflict between their work conscience and expected role, they feel that they are no longer able to do any successful task and lose the required motivation to do anything (Pajares , 2002). So the nurses cannot properly judge on their ability to perform the tasks specified in the framework of their professional career (Betz and Hackett, 1981).

\begin{tabular}{|l|l|l|l|l|l|l|l|l|}
\hline \multicolumn{6}{|l}{ Table 3: Regression between job stress components with the nursing staff' self-efficacy } \\
\hline Job stress components & $\mathrm{R}^{2}$ & Adjusted R & F & B & SD & Beta & T & P-value \\
\hline Role overload & 0.021 & 0.019 & 9.025 & -0.26 & 0.086 & -0.145 & -3.004 & 0.003 \\
\hline Role insufficiency & 0.08 & 0.078 & 38.925 & -0.58 & 0.095 & -0.284 & -6.077 & $\mathrm{P}<0.001$ \\
\hline Role ambiguity & 0.083 & 0.081 & 38.12 & -0.455 & 0.074 & -0.288 & -6.174 & $\mathrm{P}<0.001$ \\
\hline Role boundary & 0.09 & 0.088 & 41.624 & -0.706 & 0.109 & -0.30 & -6.452 & $\mathrm{P}<0.001$ \\
\hline Responsibility & 0.012 & 0.01 & 5.296 & -0.207 & 0.09 & -0.111 & -2.301 & 0.022 \\
\hline Physical environmental & 0.000 & -0.002 & 0.204 & -0.03 & 0.067 & -0.022 & -0.451 & 0.652 \\
\hline
\end{tabular}


The findings of this study showed that the sense of responsibility among nurses contributes to 0.207 in reducing their self-efficacy. Lee and Wong found that accountability was a most important job stress among nurses (Lee and Wong, 2002). Recently Raj (2016) has showed that $48.9 \%$ of ICU nurses had stress in terms of responsibility.

Bahramie et al. (2012), had earlier found that male nurses had more stress than female nurses in terms of responsibility role. The findings suggest that if nurses in the their workplace feel more stress than their counterparts, or in other words they feel more efficiency and sense of responsibility for the welfare of others in the workplace, this leads to more nurses do less effort to cope and deal with their problems, and recognize themselves weak and inefficient and easily give up and feel depressed, anxious and hopeless.

\section{CONCLUSION}

The results of this study showed that job stress among nurses influences on the personal, emotional and cognitive effectiveness in nurses and can bring some organizational outcomes such as reduced properly function in the workplace. Ultimately, this situation can lead to an increased absences, resignation, decreased job satisfaction, organizational commitment in nurses. The results of this study with the aim of the help to further understanding of personal risk and protective factors and their mechanisms can be used in interference planning so as to promote and protect the health of nurses against stressors factors.

\section{ACKNOWLEDGMENTS}

We would like to thank the Clinical Research Development Unit of Kowsar and Amiralmomenin Educational, Research and Therapeutic Centers of Semnan Uiversity of Medical Sciences for providing facilities to this work.

\section{REFERENCES}

Abdi, H. and Shahbazi, L. (2002). The relationship between occupational stress and burn out in critical nurses. Journal of Shahid Sadoghi of Yazd University Medical Sciences, 9: 58-65.

Bahrami, A. et al. (2012). Job stress among the nursing staff of Kashan hospitals.Journal of Kashan University of Medical Sciences, 15(4): 366-373.

Bandura A. (2000). Cultivate self-efficacy for personal and organization effectiveness Handbook of principles of organization behavior. Oxford, uk: Blachwell, 120-139.
Betz, N. and Hackett, G. (1981). The relationship of career related self-efficacy expectations to perceived Career options in college women and men. Journal of counseling Psychology, 28,399-410.

Brackett, M.A. et al. (2010). Emotion-regulation ability, burnout, and job satisfaction among British secondary-school teachers. Psychol Schs, 47:406-17.

Burgess, L., Irvine, F. and Wallymahmed,A. (2010). Personality, stress and coping in intensive care nurses: a descriptive exploratory study. Nursing Critical Care, 15:129-40.

Dickinson, T. and Wright, K.M. (2008). Stress and born out in forensic mental nursing; a literature review. British Journal of Nursing, 17(2); 82-7.

Farsi, Z., et al. (2010).Nursing profession in Iran : an overview of opportunities and challenges. Journal of Nursing Sciences, 7(1): 9-18.

Gholam Nezhad, H. and Nikpeyma, N. (2009). Occupational stressors in nursing. Journal of Iran Occupational Health, 6(1):22-7.

Hayes, B. et al. (2015). Douglas C, Bonner A. Work environment, job satisfaction, stress and burnout among hemodialysis nurses. Journal of nursing management, 1; 23(5):588-98.

Judge, T.A. and Bono, J.E. (2001). Relationship of core selfevaluations traits - self-esteem, generalized self-efficacy, locus of control, and emotional stability with job satisfaction and job performance: A meta-analysis. Journal of Applied psychology, 86(1), 8092.

Lee, I. and Wong, H.H. (2002). Perceived occupational stress and related factors in public health nurses. Journal of nursing Research, 10(4): 253-60.

Lim, J., Dowine, J. and Nathan, P. (2004). Nursing students' self-efficacy in providing transcultural care. Nurse Education Today, 24(6) 428-434.

Motie, M.R. et al. (2010). Prevalence of job stressors in male prehospital emergency technicians. Journal of Fundamentals of Mental Health, 12(1): 420-9.

Olson, M.A. and Hergenahahn, B.R. (2012). An Introduction to the Theories of Learning. 9th ed, Pearson Publisher.

Pajares,F. (2002). Gender and perceived self-efficacy in selfregulated learning. Theory into Practice, 91: 116-125.

Raj,, M.A. (2016). Job stress among staff nurses working in critical care units and their Socio-demographic correlates: A cross sectional survey. Global Journal For Research Analysis, 12;4(12).

Toloei,M., et al. (2006). The nurses' motivating factors in relation to patient training. Hayat, 12 (2): 43-51.

Yazdi Moghaddam, H. (2009). Estaji Z, Heydari A. Study of quality of life of nurses in sabsevar hospitals in 2005-2006. Journal of Asrar, 16(1):50-6.

Yoosefian, N. et al.(2015). The survey of job stress components of operation room staffs of teaching hospitals of Zahedan. Health Care Management, 21(6): 960-66. 